Adrián Carreras Rabasco

Lector AECID en la Universidad

de Jordania (Ammán), realizó sus estudios universitarios en la Universidad de Alicante y obtuvo la suficiencia investigadora en la misma universidad. Actualmente imparte clases de Lengua y Literatura Española en Ammán a la vez que realiza la tesis sobre las representaciones antiheroicas en la literatura hispanoamericana del siglo XX.

\section{ROBERTO BOLAÑO, LA MEMORIA ANTIHEROICA DEL EXILIO CHILENO}

\author{
ADRIÁN CARRERAS RABASCO \\ Universidad de Jordania \\ adriancarreras@gmail.com
}

\section{RESUMEN}

Este artículo se centra en la personalidad del escritor chileno Roberto Bolaño y su obra para profundizar en la relación existente entre el autor y Chile, su país de origen. Pese a haber abandonado el país siendo muy joven y a haber residido en otros países a lo largo de su vida, Bolaño nunca perdió el interés por recuperar sus raíces chilenas tanto como lo reflejan las novelas que dedica a la dictadura chilena, Estrella distante y Nocturno de Chile sobre todo, así como por reivindicar su propio origen a través de su álter ego literario Arturo Belano. En este artículo se señalarán y analizarán estas relaciones entre Roberto Bolaño y Chile a través de la visión antiheroica que el autor confiere tanto a los ambientes como a los personajes que articulan su narrativa.

Palabras clave: Antihéroe, memoria, exilio, dictadura, patria.

\section{ABSTRACT}

This article discusses the personality and the work of the Chilean writer Roberto Bolaño in an attempt to expand on the relationship between the author and his homeland Chile. Even though Bolaño left Chile at an early age and lived in many countries throughout his life, he tried to regain his roots as reflected in the novels about the Chilean dictatorship, Estrella distante and Nocturno de Chile. The author also attempts to vindicate his own origin in his literary alterego Arturo Belano. Thus, this article will highlight and analyse the relation between Roberto Bolaño and Chile through the antiheroic vision given not only to the characters but also to the settings of the narratives.

Key words: Antiheroe, memory, exile, dictatorship, homeland.

Golpeábamos, en tanto, los muros de adobe, y era nuestra herencia una red de agujeros. Anónimo de Tlatelolco, 1528

La herencia. El tesoro que nos dejaron nuestros padres o aquellos que creímos nuestros padres putativos es lamentable. En realidad somos como niños atrapados en la mansión de un pedófilo.

Roberto Bolaño, Sevilla me mata, 2003
Roberto Bolaño, la memoria antiheroica del exilio chileno ADRIÁN CARRERAS RABASCO
Casi quinientos años separan el poema anónimo de Tlatelolco, escrito tras la batalla decisiva por la conquista de Tenochtitlán en- tre el pueblo azteca y los soldados al mando de Hernán Cortés, del texto que Roberto Bolaño escribió para su última aparición pública 
en Sevilla. Asombra comprobar cómo, desde la escritura del primero hasta el último, parece trazarse una línea continua que atraviesa cinco siglos donde no parece prevalecer otro sentimiento más allá del desamparo y el horror del pueblo americano, ya sea precolombino ya en la segunda mitad del siglo xx. En las últimas décadas del pasado siglo así como en la primera del xxi, cuando aún no han dejado de sangrar las heridas provocadas por las continuas guerras y los regímenes dictatoriales, el ser humano se ve abocado a un mundo que no comprende y del cual no se siente parte. Entre los escritores que en la última década han dado cuenta de este sentimiento, Roberto Bolaño es uno de los pocos que han sido llamados a ocupar un puesto privilegiado en el Olimpo de los grandes nombres de las letras hispanoamericanas. Pese a la fama que adquirió a raíz de sus obras más premiadas, Los detectives salvajes o 2666, o las polémicas que desató como feroz crítico del canon literario, su trágica muerte prematura en 2003, a los cincuenta años, en pleno despegue de su reconocimiento editorial, así como su narrativa y poesía caracterizadas por el prosaísmo verbal y por personajes oscuros y marginales cuyas vidas transcurren en ambientes propios de la novela negra con tintes poeanos, le han conferido el marbete de escritor maldito. Bolaño forma parte de un grupo de escritores hispanoamericanos que en los últimos años dejaron el continente para afincarse en Cataluña. Pocos fueron los autores connacionales a los que veneró, salvo la gran excepción de Nicanor Parra. Su vida y sus recuerdos parecen llevarnos más a menudo a México o a Blanes, en la costa catalana, donde encontró su más estable residencia. Pero, aunque a primera vista en la biografía del autor chileno se nos presente a sí mismo apátrida y voraz crítico a la hora de mirar hacia su país de origen, en su obra, sobre todo aquella escrita durante su primera época, encontramos múltiples referencias a los acontecimientos políticos de su país que lo mantuvieron lejos de Chile y a los personajes que vivieron desde la sombra las atrocidades cometidas durante la dictadura del general Augusto Pinochet.

Partiendo de esta concepción del mundo según Bolaño, es interesante hacer hincapié en su condición de exiliado ideológico. Su narrativa se funda en el desamparo y la desolación de quienes reconocen la derrota ideológica. A partir del momento en que toda creencia resulta falsa, el individuo se ha de mover en su propia soledad. Se puede decir con Chiara Bolognese que la marginalidad de los personajes del escritor chileno está vinculada al tema del exilio y a la asfixia existencial que les provoca vivir lejos de una patria que les es hostil. Es por ello interesante destacar que el legado literario de Roberto Bolaño se hace eco, una vez más, de las barbaries que azotan el continente hispanoamericano continuando una línea que se iniciaría con los primeros testimonios de la conquista tal como recoge León Portilla en Los últimos días del sitio de Tenochtitlán y presenta muy diversas manifestaciones a través de la historia, como podemos comprobar en los diarios de Colón o en los primeros cronistas, Las Cartas de Relación de Hernán Cortés, Los Naufragios de Álvar Núñez Cabeza de Vaca o la figura de Lope de Aguirre, así como durante los años contiguos a la Guerra de Independencia como el Lazarillo de Ciegos Caminantes (1773) de Alonso Carrió de la Vandera; El Periquillo Sarniento (1816) de José Joaquín Fernández de Lizardi, e incluso los discursos de Simón Bolívar (1815), por citar algunos ejemplos representativos, hasta llegar al siglo $\mathrm{xx}$, donde autores como Julio Cortázar en su Libro de Manuel (1973-1974) o Juan Rulfo en El llano en llamas y Pedro Páramo.

Entre el abundante corpus literario que Bolaño produjo en su breve carrera, se encuentra un grupo de novelas que constituiría un ciclo narrativo dedicado a Chile y a los años de la dictadura en que destaca el compromiso del autor por el país que lo vio nacer. Estas novelas comparten el ánimo de evocar los acontecimientos que marcaron a aquellos individuos cuya vida se desenvuelve en la periferia, al margen de las decisiones importantes, desde la memoria marcada por el horror. Siguiendo a Chiara Bolognese «el hilo de todas sus creaciones es la evocación de vidas -en su mayoría de jóvenes latinoamericanos- encaminadas hacia el abismo, existencias de personajes que quieren escribir pero nunca logran hacerlo con éxito» (Bolognese, 2009, p. 53). Chile, como México, constituye el escenario en que tuvieron lugar los acontecimientos que cambiaron su concepción del mundo y la de su generación. La escritura se entiende como un intento de mantener vivo el recuerdo de aquellos años y el fracaso se comprende como la incapacidad de la memoria de superar el horror. Tal como dice en su «Discurso de Ca-

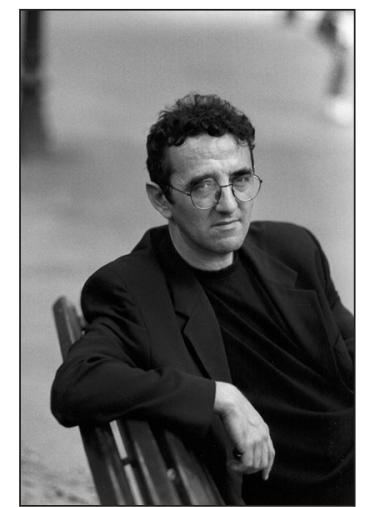

Roberto Bolaño.
Roberto Bolaño, la memoria antiheroica del exilio chileno ADRIÁN CARRERAS RABASCO 


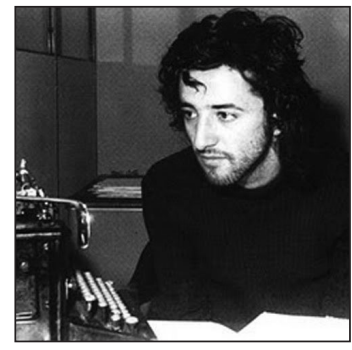

Roberto Bolaño. racas», al recibir el Premio Rómulo Gallegos: «A veces la patria de un escritor no es la gente sino su memoria» (Bolaño, 2008b, p. 36). De este modo, tanto los escenarios como el tiempo en que se desarrollan las historias están narrados desde la memoria de sus narradores. En el presente artículo me interesa rescatar aquellos testimonios del horror que Roberto Bolaño recoge en sus novelas dedicadas a la dictadura en Chile. Estas novelas son, sobre todo, Estrella distante y Nocturno de Chile. Por otro lado, al hablar del exilio chileno se hace imprescindible acudir al personaje que constituyó el alter ego de su autor, Arturo Belano, personaje para cuya descripción acudiremos a Los detectives salvajes y a Amuleto, y que nos servirá de mejor ejemplo de exiliado chileno errante.

\section{Chile como la patria hostil}

De acuerdo con Patricia Espinosa (2002, p. 128), la visión que se muestra de Chile durante la dictadura viene dada por unos personajes que se ubican en los márgenes de las metrópolis a fin de proyectar un retrato del conflicto existente entre centro y periferia. El enfoque de las historias del autor casi siempre está fundado en una mirada a los extramuros de la metrópolis. Chiara Bolognese ha señalado, con respecto a esto, que las narraciones del escritor chileno «retratan el encuentro, mejor dicho el choque, entre la macrorrealidad de las metrópolis y la microrrealidad de las vidas de los protagonistas» (Bolognese, 2009 , p. 74). Sus personajes son testimonio del conflicto entre una realidad hostil y la impotencia de quienes se ven inmersos en un mundo yermo. En estos escenarios se configura su discurso de la marginalidad y el desarraigo, como muestra Diego Soto en Estrella distante, quien «aparecía y desaparecía como un fantasma en todos los lugares donde había pelea, en todos los lugares en donde los latinoamericanos, desesperados, generosos, enloquecidos, valientes, aborrecibles, destruían y volvían a destruir la realidad en un intento último abocado al fracaso» (Bolaño, 2009a, p. 66). La mayoría de sus personajes, como ha señalado Chiara Bolognese, vive en lugares caracterizados por «la destrucción y la fealdad; todo es igual, todo se confunde allí donde dominan la pobreza y la marginalidad» (Bolognese, 2009, p. 70). De este modo, habríamos de hablar de una estética dirigida a elaborar un discurso surgido desde la voz del marginado. El sentimiento de desarraigo lleva a estos personajes a una continua e infructífera búsqueda. Asimismo, esta autora afirma que a Roberto Bolaño «le interesa relatar los acontecimientos de las zonas límites [y que] su intención no difiere mucho de cuando describe las metrópolis reales de Hispanoamérica o Europa» (Bolognese, 2009, p. 75). Dentro de este espacio hostil nadie queda libre del sentimiento aciago que suscita cualquier situación o elemento del paisaje, Chile ocupa el puesto de espacio hostil por antonomasia. En un mundo donde dominan el miedo y la opresión, la pasividad impide cualquier intento de mejorar la situación. La dictadura y los múltiples crímenes perpetrados por sus militantes o simplemente un profundo sentimiento de desidia configuran escenarios en los que la vida de los personajes queda continuamente puesta a prueba.

El momento histórico en Hispanoamérica que retrata Bolaño, especialmente en Chile y en México, difícilmente podría ser enfocado, con Gonzalo Aguilar, como un mundo inmerso en el terror, como uno de los rasgos que caracterizan la narrativa de la generación de Roberto Bolaño: «Entre aquellos años de euforia optimista y los actuales, median nada menos que los genocidios y el desvanecimiento de América Latina como alternativa cultural» (Aguilar, G. 2002, p. 148). Estos acontecimientos marcan la manera de enfrentarse al mundo y a la vida de sus personajes, individuos marcados por el horror. De acuerdo con Chiara Bolognese «La dureza de la realidad del Chile y del México de los años sesenta y setenta deja sus rastros en los individuos que la sufrieron y produce modificaciones en sus personalidades» (Bolognese, 2009 , p. 143). Este testimonio de la masacre y del horror constituye, pues, el tema principal de muchas de sus «novelas políticas» o «memorias politizadas». Así, en este artículo quiero centrar mi atención en las novelas que dan cuenta de la dictadura militar chilena, las novelas Nocturno de Chile y Estrella distante sobre todo, y por otro lado, la visión del propio autor a través de su alter ego, el cual desfila por muchas de sus novelas, Arturo Belano. La sentencia «Soñábamos con utopía y nos despertamos gritando» incluida en el «Manifiesto infrarrealista» durante los años mexicanos del escritor chileno resume a la perfección la índole del desastre presentado 
en las narraciones. Desde sus comienzos, Roberto Bolaño mostró una firme inclinación a retratar personalidades afiliadas al movimiento nazi, como aparece en el mosaico que conforma La literatura nazi en América; Estrella distante supone, a nuestro juicio, el primer y más célebre paso, con el permiso de Los detectives salvajes, hacia la inclusión del autor en el testimonio del horror en el transcurso de aquellos años.

Si bien las primeras páginas de Los detectives salvajes nos describen los años previos al gobierno de Allende como un momento en que se percibía una esperanza para la utopía:

Hablábamos [...] no sólo de poesía, sino de política [...] de revolución y lucha armada; la lucha armada que nos iba a traer una nueva vida y una nueva época, pero que para la mayoría de nosotros era [...] como la llave que nos abriría la puerta de los sueños, los únicos por los cuales merecía la pena vivir. Y aunque vagamente sabíamos que los sueños a menudo se convierten en pesadillas, eso no importaba. (Bolaño, 2008a, p. 13)

Este sentimiento gira radicalmente hacia la reflexión en torno a las significaciones del Golpe militar, de la dictadura y de la postdictadura. El testimonio viene dado de mano de Arturo B., quien reflexiona que «en la América Latina de los setenta, sólo era eso, una vida triste, llena de pequeñas mezquindades, algunas hechas sin ni siquiera mala intención» (Bolaño, 2009a, p. 68). En este ambiente donde se impone la frustración ante la utopía desaparecida y la caída de los ideales, Carlos Wieder, alias Ruiz-Tangle, encarna un héroe de la dictadura de Augusto Pinochet cuyos actos de sadismo lo llevan a convertir su demencia en su obra de arte. Wieder encarna, como el propio Roberto Bolaño afirmó, «una aproximación [...] al mal absoluto» (Bolaño, 2008 b, p. 20) tras la fachada de muchacho «encantador» (Bolaño, 2009a, p. 44). Este antihéroe actuará dentro de la dictadura como el héroe nacional a través del cual Roberto Bolaño transmite los ideales sobre los que se funda el gobierno de Augusto Pinochet: la violencia y el sadismo genocida; de ahí que su primer acto de poesía revolucionaria sea el asesinato de las gemelas Garmendia seguido de la escritura con humo desde su avión de los primeros versos del Génesis, acto que, como ha visto Celina Manzoni, «se lee como amenaza, crea expectativa, miedo y una mudez que se acentúa cuando al final escribe su propia última palabra: 'APRENDAN'» (Manzoni, 2002, p. 44). Ante ese espectáculo Arturo B. nos da algunas claves del sentimiento imperante en tiempos de la dictadura: «Hasta ese momento nunca había visto tanta tristeza junta» (Bolaño, 2009a, p. 39). Asimismo, pone en el grito desesperado de uno de los asistentes el testimonio de un pueblo: «sólo somos chilenos, señor, dijo, inocentes, inocentes» (Bolaño, 2009a, p. 37). En efecto, como hemos señalado, la tristeza y el desconsuelo se presentan como los sentimientos generalizados en el pueblo chileno durante los años de dictadura. $\mathrm{Y}$ este sentimiento se traduce en el mismo personaje al ser presentado como una víctima más del momento histórico; así lo entiende, desde su perspectiva como participante de la represión, el oficial que le acompañó en algunas misiones:

El teniente de la Fuerza Aérea sólo hizo lo que todos los chilenos tuvieron que hacer o quisieron y no pudieron hacer. En las guerras internas los prisioneros son un estorbo [...] y ¿Quién en el medio del terremoto de la historia, podía culparlo de haberse excedido en el cumplimiento del deber? (Bolaño, 2009a, p. 118)

La historia de Wieder queda vinculada a la del destino de los chilenos, «quienes asombrados la escuchan, entienden que en parte es su historia, $[\ldots]$ y en parte es la historia de Chile», según recoge Ezequiel de Rosso (2002, p. 60) en su artículo. Una situación similar la encarna el personaje del Rey que regula la prostitución masculina en la colonia Guerrero en Amuleto; este vive en «una pesadilla inconclusa de la que hubiera querido escapar mediante la violencia» (Bolaño, 2009b, p. 85).

Como este, los personajes inmersos en la dictadura asisten a la conversión de la violencia en un espectáculo cotidiano y la realidad se transforma en algo monstruoso y lleno de maldad: «me parece que estamos entrando en el campeonato mundial de la fealdad y la brutalidad» (Bolaño, 2009a, p. 27). Pese a estas palabras, Celina Manzoni (2002, p. 49) ha indicado que cabe destacar la ausencia de un propósito de denuncia en la novela, pues en lugar de un sentimiento de indignación o de rabia, el discurso está narrado desde la frialdad y la resignación de quien es consciente de que ya no hay lugar para los sueños. Tomando el tema del naufragio, símbolo de catástrofes
Roberto Bolaño, la memoria antiheroica del exilio chileno ADRIÁN CARRERAS RABASCO 
de índole social así como del desplazamiento de las masas recogido en la literatura desde tiempos remotos, Arturo B. relata un sueño que tuvo:

En ese instante el galeón comenzaba a hundirse y todos los sobrevivientes nos convertíamos en náufragos. En el mar, flotando agarrado a un tonel de aguardiente, veía a Carlos Wieder. Yo flotaba agarrado a un palo de madera podrida. Comprendía en ese momento, mientras las olas nos alejaban, que Wieder y yo habíamos viajado en el mismo barco, sólo que él había contribuido a hundirlo y yo había hecho poco o nada por evitarlo (Bolaño, 2009a, p. 131).

Chiara Bolognese nos presenta Estrella distante como la evocación del tiempo de la dictadura chilena desde el «relato de los hechos más crueles perpetrados por los militares del régimen, de la denuncia de cómo esta violencia desgarradora afectó a toda una generación de jóvenes que tuvieron que elegir entre marcharse del país o aceptar vivir en el silencio del miedo y de la negación» (Bolognese, 2009, p. 147). Haya o no denuncia en esta novela, lo cierto es que el terror del régimen queda narrado desde la perspectiva de quienes lo padecieron, las generaciones más jóvenes.

Y si bien el horror de estos años se narra en Estrella distante desde el punto de vista de los sometidos, es decir los chilenos, la dictadura chilena también será tratada desde la visión del poder en Nocturno de Chile. En esta novela toma la figura del sacerdote del Opus Dei Sebastián Urrutia Lacroix para hacerse eco del discurso del poder a partir de las reflexiones del anciano en su lecho de muerte. Gonzalo Aguilar sostiene que Sebastián Urrutia Lacroix encarna la figura principal de un relato sobre «los equívocos del amor a la patria» (Aguilar, G. 2002, p. 150). En él queda presente el sentimiento de melancolía más profundo. Al final de su vida el sacerdote rememora los años en que actuó al servicio del gobierno de Augusto Pinochet dándole clases de marxismo y cómo fue testigo de torturas que tenían lugar en la misma casa donde realizaban reuniones literarias. Estos recuerdos provocan en el cura un delirio melancólico que, como también ha señalado Gonzalo Aguilar, no encuentra consuelo «ni en los libros ni en la vida ni en la memoria» (Bolaño, 2009c, p. 131). Ya en los últimos días de su vida, se siente víctima aterrada de una pesadilla muy real. El cura protagonista es un hombre débil, postrado a la voluntad de las fuerzas del régimen de Pinochet. La maldad envuelve la atmósfera de esta novela donde convive el sentimiento común de opresión y la desesperación final del sacerdote, en el límite de la demencia, cuando se hace evidente la imposibilidad de defender el mundo en que ha estado inserto toda su vida.

Como en todas las novelas de Roberto Bolaño, la literatura se sitúa en primer plano ofreciendo, siguiendo a Paula Aguilar, un panorama donde se muestra cómo «la experiencia dictatorial significó un quiebre en la figura del escritor comprometido y de los ideales utopistas» (Aguilar, P., 2008, p. 127) así como la reflexión en torno a las significaciones de la dictadura y la postdictadura. Ciertamente, como también ha señalado esta autora, el nocturno, la melancolía y el crepúsculo aparecen como «símbolos del presente» (Aguilar, P., 2008, p 128). Si Estrella distante presenta un mundo en que la literatura y el terror de los crímenes y el sadismo van de la mano, como bien ha señalado Maria Luisa Fischer (2008, pp. 145-162), Nocturno de Chile retoma esta dirección, por un lado, al presentarnos la casa de María Canales, lugar donde se realizan las reuniones literarias a la vez que en el sótano de la misma, su marido, Jimmy Thomson, practica la tortura a presos políticos del régimen: «los subversivos pasaban por los sótanos de Jimmy, en donde este los interrogaba, [...] En su casa, por regla general, no se mataba a nadie. Sólo se interrogaba, aunque algunos murieron» (Bolaño, 2009c, p. 141). Por otro lado, también nos presenta los retratos fugaces de las principales figuras del régimen chileno en los que encarna la evidencia del fracaso literario en el Chile de aquellos años. El mismo dictador Augusto Pinochet se presenta como una figura de renombre en el panorama crítico de su tiempo: «Leo y escribo. Constantemente. Eso no es algo que se pueda decir de Allende o de Frei o de Alessandri, ¿verdad?» (Bolaño, 2009c, p. 118).

Al margen de la precaria situación literaria retratada, fuera del ambiente próximo al régimen, el mundo exterior se presenta como un lugar decadente totalmente opuesto a ese donde reside el sacerdote. Cuando el padre Urrutia Lacroix sale de la mansión de su contertuliano Farewell, llega a una cabaña en la que residen los peones del literato. Cuando uno de los labriegos se dirige a él, el sacerdote manifiesta su sensación de «miedo y asco» 
(Bolaño, 2009c, p. 20). La revelación de estas gentes que consiguen alterar su «equilibrio mental y físico» (Bolaño, 2009c, p. 31) se centra en la descripción de su fealdad: «todos eran feos. Las campesinas eran feas y sus palabras incoherentes. El campesino quieto era feo y su inmovilidad incoherente. Los campesinos eran feos y su singladura en zigzag incoherente» (Bolaño, 2009c, p. 20). Frente a esta fealdad entre el pueblo, Paula Aguilar ha señalado la presentación de un anti-tipo en el niño Canales, hijo de Marina Canales, «cuyos ojos azules 'ven lo que quieren ver' y provocan ganas de llorar en el cura» (Bolaño, 2009 c, p. 20). Así pues, el retrato que ofrece Urrutia Lacroix del Chile de su tiempo es el de unas gentes «feas» e «incoherentes» frente a aquellos que permanecen próximos o ajenos a la situación. Será precisamente la imagen de esta gente y del horror de las torturas en el sótano de María Canales, como veremos en el epígrafe siguiente, lo que acabará por desarticular el discurso conformista con el poder del sacerdote.

El retrato del Chile de aquella época se extiende al resto de Hispanoamérica con el cuadro de un pintor guatemalteco titulado Paisaje de Ciudad de México una hora antes del amanecer. De él dice que «algunos barrios parecían olas. Otros barrios parecían negativos de fotografías. No se percibían figuras humanas pero sí, aquí y allá, esqueletos difuminados que podían ser tanto de personas como de animales» (Aguilar, P., 2008, p. 129). Esta imagen se acentúa en el lecho de muerte del sacerdote, en el delirio provocado por la revelación del horror: grupos de niños y jóvenes que «cruzaron el valle y se despeñaron en el abismo» (Bolaño, 2009c, 153), abismo que representa el futuro para las futuras generaciones hispanoamericanas.

Patricia Espinosa ha señalado que el hecho de que Bolaño emplee como narrador de un relato sobre los crímenes de la dictadura a un militante del bando de Augusto Pinochet está motivado «no para enmascarar una denuncia, sino para hacer estallar al poder desde su propia realidad discursiva» (Espinosa, 2002, p. 128).

Tanto la imagen interior como los escenarios exteriores en la obra de Roberto Bolaño quedan configurados por un sentimiento apocalíptico unitario cuyo origen radica en el fracaso que supuso para el continente la germinación de regímenes totalitarios y de

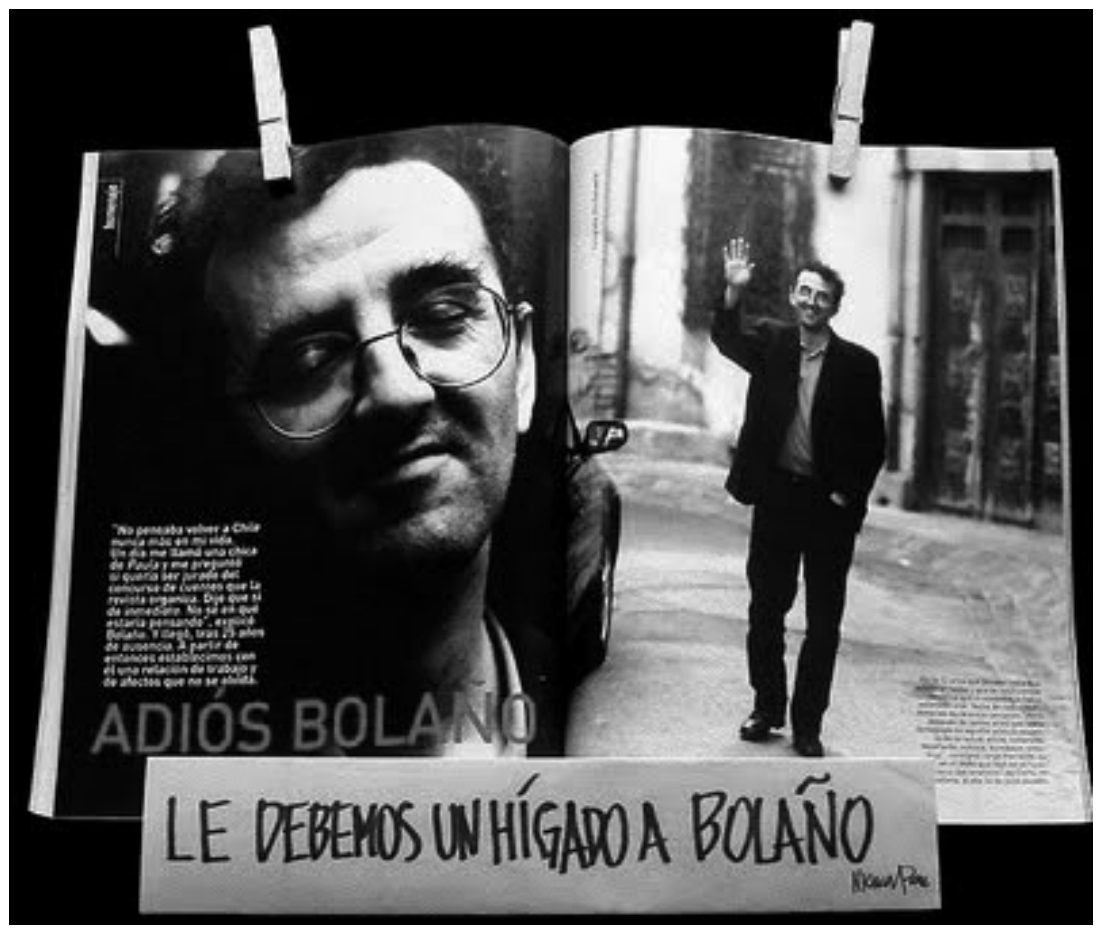

Roberto Bolaño.

crímenes sin sentido. Ciertamente, el núcleo de las narraciones bolañanas constituye un hecho; todas ellas se articulan en torno a algún acontecimiento que marca la existencia de los personajes. Cada suceso adquiere protagonismo en el relato de cada individuo y muestra su índole a través de los diferentes enfoques que los personajes aportan. De esta forma conocemos desde diferentes ángulos los múltiples puntos de vista que un mismo acontecimiento es capaz de generar.

Sus personajes, ya exiliados, ya residentes en Hispanoamérica, yerran por las páginas de sus novelas como parias errabundos en el abismo en que se ha convertido Hispanoamérica para sus habitantes. Todos ellos son portadores de un trauma desatado por un suceso terrible que marca sus vidas y en ocasiones las hunde irremediablemente en la miseria. Se trataría, por tanto, de una «antiépica» articulada a través de un discurso antiheroico. De acuerdo con Ignacio Echevarría, «por la obra de Bolaño transitan -errantes, fantasmales- los náufragos de un continente en el que el exilio es la figura épica de la desolación y la vastedad» (Echevarría, 2002, p. 193). Esta condición de la patria como territorio hostil habría de ser el primer rasgo que caracteriza al antihéroe bolañano. Los países que encontraremos a lo largo de su producción literaria antiheroica del exilio chileno ADRIÁN CARRERAS RABASCO
Roberto Bolaño, la memoria 
serán siempre terrenos áridos donde el ser humano agoniza y la única salvación del terror estará en huir, sólo que la búsqueda de la utopía ya no es posible. Como veremos, los personajes de Bolaño jamás habrán de encontrar una Ítaca donde rehacer unas vidas que se mueven más allá del precipicio.

\section{Arturo Belano, el antihéroe del exilo chileno}

Poco se ha dicho acerca de la ausencia de los protagonistas bolañanos. Al contrario que los personajes significativos para la cultura o la sociedad, los individuos que retrata representan el sector de la sociedad que sufre los daños colaterales de los grandes acontecimientos históricos. Sus vidas permanecen sumergidas «en la tristeza cotidiana» (Bolaño, 2004, p. 703 ) donde lo incógnito y el vacío son las únicas opciones posibles: «Ganas de vivir, ganas de hacerle la lucha [...] ¿pero hacerle la lucha a qué, a lo inevitable? ¿Luchar contra quién? ¿Y para conseguir qué? ¿Más tiempo, una certeza, el vislumbre de algo esencial? Como si hubiera algo esencial en este [...] país» (Bolaño, 2004, pp. 703-704). En muchos casos, la narración se dirige a un personaje del que poco sabemos directamente por sí mismo sino sólo por lo que relatan los muy numerosos testimonios que se hacen eco de él. Dentro del amplio mosaico de personalidades recogidas en la obra de Roberto Bolaño, el relato de la vida y de los avatares de Arturo Belano resulta especialmente familiar a quienes están al corriente de la biografía que divulgó sobre sí mismo el escritor chileno. Si en los epígrafes anteriores repasamos algunas ideas comunes a los personajes del ciclo chileno, en las siguientes líneas vamos a centrarnos en el antihéroe Arturo Belano por tratarse probablemente del personaje más representativo de su primera etapa literaria. Entre la biografía del autor y las diferentes peripecias vividas por su personaje en numerosos cuentos así como en las novelas Estrella distante, Los detectives salvajes o Amuleto (sin contar los datos autobiográficos que reflejan los personajes sudamericanos de La pista de bielo, Remo Morán y Gaspar Heredia), la sospecha no puede hacer más que crecer ya desde que se identifica la clara similitud entre los apellidos del personaje, «Belano», y de su autor, «Bolaño». La crítica, asimismo, ha situado el origen del nombre Arturo en el escritor francés Arthur Rimbaud (Martín y Bagué,
2008, pp. 459-460), a quien el autor de Los detectives salvajes ya aludía en el manifiesto infrarrealista de 1976: «iRimbaud, vuelve a casa!» (Bolaño), donde anima, como el poeta, a «subvertir la realidad cotidiana de la poesía actual» (Bolaño). Los poetas real visceralistas de Los detectives salvajes aluden a él como epígono de la poesía que ellos persiguen, «mi generación leyó a Marx y a Rimbaud hasta que se le revolvieron las tripas» (Bolaño, 2008a, p. 528). De hecho, el poeta Arthur Rimbaud y el personaje bolañano, Arturo Belano, comparten el mismo misterioso final; así como la última pista que se tuvo del poeta francés es que encontró su retiro de la poesía con una silenciosa vida en África y Oriente Medio, al poeta real visceralista se le pierde la pista en África, donde dice haber ido "para tener una muerte bonita, una muerte fuera de lo normal» (Bolaño, 2008a, p. 528).

Como es conocido, la suerte de Roberto Bolaño no fue la de su personaje, pues mientras este acabó sus días sumido en el fracaso renegando del mundo, el escritor chileno feneció en el momento en que su carrera literaria comenzaba a despegar. Pese a las semejanzas que puedan identificarse durante la comparación entre la vida del autor y la de su personaje, el carácter creativo y polémico del escritor nos lleva a cuestionarnos cuánto existe de realidad en la biografía de Arturo Belano y cuánto de literatura en la de Roberto Bolaño. El caso más conocido es el referido al golpe de Estado en Chile y al episodio que cuenta: cómo pudo escapar de una muerte segura gracias a que, dos viejos compañeros del colegio que lo custodiaban, lo dejaron escapar antes de la ejecución. Este relato incluido en el cuento «Detectives» de Llamadas telefónicas, hace mención a cómo esto le sucedió a Belano del mismo modo que el «Autorretrato» aparecido en Entre paréntesis lo cuenta atribuido al escritor. Roberto Bolaño y Arturo Belano comparten realidad y ficción de tal manera que al hablar del «antihéroe chileno» podemos referirnos tanto al escritor como a la creación. Habida cuenta de esto, cabe matizar que Arturo Belano representa la biografía de la juventud del autor. Los avatares antiheroicos de Belano se entienden en tanto que los interpretamos como el conjunto de una visión romántica del mundo que queda frustrada por los acontecimientos de su tiempo.

Auxilio Lacouture, la heroína superviviente de los asesinatos de Tlatelolco que 
permaneció escondida en los aseos de la universidad, nos relata la juventud de Arturo Belano en Los detectives salvajes: "Yo me hice amiga de esa familia. Una familia de chilenos viajeros que había emigrado a México en 1968» (Bolaño, 2008a, p. 195). Los orígenes del poeta real visceralista se muestran totalmente desmitificados y lejos de una apariencia hostil, ni siquiera se aduce una razón política de la emigración sino que alude a ellos como «viajeros». Belano en particular es descrito como un joven ingenuo que posteriormente sufre la caída de sus ideales. El cambio en el personaje tiene lugar cuando, como todo héroe, emprende el viaje iniciático. Cuenta Lacouture que, a los dieciséis años, el joven Belano decide viajar a Chile para apoyar al Gobierno de Salvador Allende. Lo describe como «el viaje iniciático de todos los pobres muchachos latinoamericanos, recorrer este continente absurdo» (Bolaño, 2008a, p. 195). Como todo héroe tradicional, con su vuelta a la patria encontramos un Arturo Belano cambiado: "Cuando Arturo regresó a México, en enero de 1974, ya era otro. Allende había caído y él había cumplido con su deber [...], había cumplido su conciencia, su terrible conciencia de machito latinoamericano, en teoría no tenía nada que reprocharse» (Bolaño, 2008a, p. 195). En Amuleto, Auxilio Lacouture continúa la descripción del cambio de personalidad en el personaje:

Llegó Arturito de Chile y ya era otro [...] algo había cambiado o había crecido o había cambiado y crecido al mismo tiempo [...] sus amigos lo empezaron a mirar como si fuera otro aunque él fuera el mismo de siempre [...] Todos esperaban de alguna manera que él abriera la boca y contara las últimas noticias del Horror (Bolaño, 2009b, p. 69).

Este viaje marca una nueva manera de enfrentarse a la vida; Arturo Belano cambia sus amistades y comienza a reunirse con los poetas marginales que completarán el grupo de los real visceralistas: «fue normal que Arturo se uniera a ellos y se alejara paulatinamente de sus amigos. Ellos eran los niños de la alcantarilla y Arturo siempre había sido un niño de la alcantarilla» (Bolaño, 2008a, p. 70). Existe asimismo la crítica del ideal heroico literario frente al héroe realista que representa Arturo Belano a su regreso:

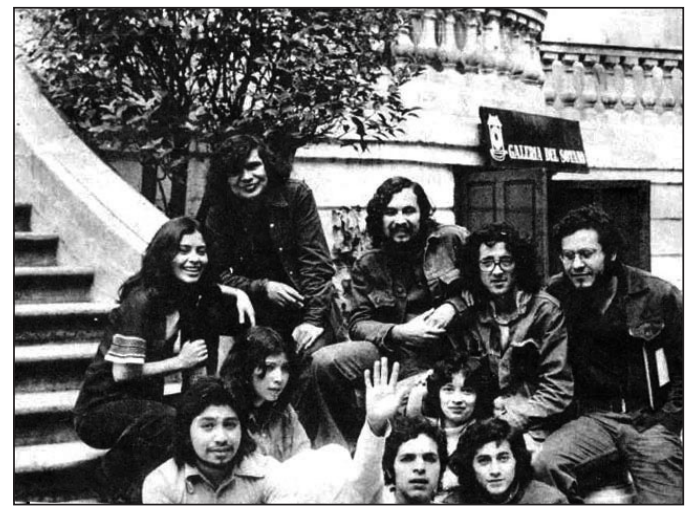

Infrarrealistas.

Comenzó a reírse de sus antiguos amigos, a perdonarles la vida, a mirarlo todo como si él fuera el Dante y acabara de volver del Infierno, qué digo el Dante, como si fuera el mismísimo Virgilio [...] Comenzó a fumar marihuana, vulgo mota y a trasegar con sustancias que prefiero ni imaginármelas (Bolaño, 2008a, p. 196).

Es interesante analizar el grupo literario marcado por la tendencia del Real visceralismo. En la construcción de este grupo identificamos muchos elementos propios del Romanticismo y de sus sucesores decadentistas. Se trata de un grupo de poetas que vive la literatura como experiencia personal, que como los románticos busca sus modelos en las grande figuras heroicas del pasado. Los héroes de los real visceralistas son Arthur Rimbaud, Charles Baudelaire y el conde Lautreamont, escritores decadentistas cuya fama trascendió lo estrictamente literario alcanzando el rango de personajes en sí mismos. De este mismo modo, los poetas del real visceralismo son parias apátridas que viven experiencias al límite y Arturo Belano será, junto a Ulises Lima, el máximo representante. Los poetas real visceralistas habrán de acabar sus días en el más absoluto anonimato, sin haber siquiera publicado un poema en alguna antología. A este respecto viene el relato de Lisandro $\mathrm{Mo}-$ rales en Los detectives salvajes, quien se ve en la ruina tras editar una revista en que publican los real visceralistas:

Cuando por fin apareció el libro de Arturo Belano, éste ya era un autor fantasma y yo mismo estaba a punto de empezar a ser un editor fantasma. Siempre lo supe. [...] Yo sabía que sacando el libro de ese muchacho jugaba con fuego. Me quemé y no me quejo (Bolaño, 2008a, p. 300).
Roberto Bolaño, la memoria antiheroica del exilio chileno ADRIÁN CARRERAS RABASCO 
Además, frente al relato de la gente de su entorno, que son los únicos que definen a Arturo Belano y a Ulises Lima como poetas, el resto de testimonios únicamente los conoce por ser camellos, como Alfonso Pérez Camarga: «Belano y Lima no eran revolucionarios. No eran escritores. A veces escribían poesía, pero tampoco creo que fueran poetas. Eran vendedores de droga» (Bolaño, 2008a, p. 196). Pocos años después «ese grupo más bien patético» (Bolaño, 2008a, p. 454) cae en el olvido o, como afirma uno de sus componentes, Rafael Barrios, «sólo sé que en México ya no nos conoce nadie y que los que nos conocen se ríen de nosotros (somos el ejemplo de lo que no se debe hacer) y tal vez no les falte razón» (Bolaño, 2008a, p. 345). En todo este movimiento prevalece una poética del desamparo y del fracaso postulada por el modo de vida de sus escritores; sus máximos representantes son un chileno que ha perdido su patria y un paria mexicano: «Hay una literatura para cuando estás ávido de conocimiento. Y hay una literatura para cuando estás desesperado. Esta última es la que quisieron hacer Ulises Lima y Belano» (Bolaño, 2008a, p. 201). El mismo grupo literario desaparece bajo la marca del fracaso y el olvido. Es significativo a este respecto el relato de Felipe Müller, quien cuenta su vida en Barcelona junto a Arturo Belano y cómo acaban publicando un relato en que ambos renuncian a la poética real visceralista. El motivo, sin embargo, está despojado de profundidad literaria, más bien de razones extraliterarias:

No abjuramos de nada, no echábamos pestes sobre nuestros compañeros en México, simplemente decíamos que nosotros ya no formábamos parte del grupo. En realidad, estábamos muy ocupados trabajando e intentando sobrevivir (Bolaño, 2008a, p. 255).

Arturo Belano emigra a Europa y pronto se asienta, como su autor, en un pueblo cercano a Barcelona, donde consigue varios trabajos entre los que destaca el de vigilante de un camping (Bolaño, 2008a, p. 196), al igual que el propio autor afirma en su biografía. Destacan los relatos de Mary Watson y de Alain Lebert en Los detectives salvajes, donde tanto Arturo Belano como Ulises Lima, pero sobre todo el primero, aparecen como personajes extraños y anónimos. Es interesante el episodio de Mary Watson (pp. 244-259) en el que cuenta la aventura de la joven inglesa por España y cómo conoce al vigilante de un camping en Castelldefels tras el que se oculta el carácter de Belano, aunque en el relato no se revela su nombre. Es especialmente representativo del desplazamiento del personaje a un segundo plano. En el relato de Mary Watson, Arturo Belano representa a un vigilante con el que tiene una aventura pasajera y nada significativa en su vida; como muestra el final del relato: "conocí a otra persona y dejé de pensar en él» (Bolaño, 2008a, p. 345). Como estas, las demás historias amorosas que giran en torno a Arturo Belano están igualmente desprovistas de un aura mitificadora del amor como salvación por representar en su mayoría relatos en los que prima la presencia del sexo sobre la relación sentimental. Es más, durante su última etapa en Barcelona, Belano aparecerá como un escritor marginal, separado de su mujer y con un hijo, arrastrando el trauma por una relación amorosa fallida con una mujer que lo rechazó (Bolaño, 2008a, p. 581).

En su última aparición, Arturo Belano es reportero de un periódico español en África, a donde viaja con la intención de acabar allí sus días. Aquejado por una enfermedad hepática, la misma que su creador Roberto Bolaño padecía desde 1992, sigue cuidadosamente un tratamiento a base de medicamentos. Esto hace pensar a Jacobo Urenda, el narrador de la aventura de Belano en África, que realmente no quería morir: «Su historia era bastante incoherente. Por un lado saqué la conclusión de que la vida no le importaba nada [...]. Pero por otro lado, y esto resultaba paradójico, él se cuidaba, se tomaba religiosamente sus pastillas» (Bolaño, 2008a, p. 528). Aunque Arturo Belano cesa en su intención de morir, sin embargo carece de dinero con el que volver a Cataluña y su rastro se pierde finalmente cuando se dirige a cubrir la noticia de una escaramuza entre dos milicias rivales:

El chileno viaja a Angola y Liberia, dos países destrozados por graves conflictos internos. Esta realidad de imparable lucha causa un cambio muy profundo en él, que, tan sólo veinteañero, había sido apresado por apoyar a Allende. Ahora, cuarentón y con graves problemas de salud, se encuentra otra vez en contacto con la violencia y la muerte, y parece que se involucra conscientemente en esta situación, a fin de acabar con su vida (Bolognese, 2009, p. 149).

Pese a actuar consciente, el relato final de Arturo Belano no es en modo alguno el de un 
héroe que se enfrenta decidido a una muerte segura sino de un reportero de prensa temeroso ante el destino absurdo al que se enfrenta:

La cara de López Lobo estaba impasible. Sabe que ahora va a morir y está tranquilo, pensé. La cara de Belano, por el contrario, parecía la de un demente: en cuestión de segundos era dable ver en ella un miedo espantoso o una alegría feroz. Lo cogí de un brazo e irreflexivamente salí con él a dar un paseo por el exterior (Bolognese, 2009, p. 196).

De algún modo, la grandeza de Arturo Belano reside en el retrato destemplado del destino americano, exiliados de espíritu condenados a errar. Sus viajes no constituyen caminos de iniciación entendidos en su sentido clásico, sino caminos de huida. El regreso a Chile puede entenderse como un viaje de iniciación o como la culminación de un viaje de iniciación que termina con un retorno, solo que el regreso se ve truncado por el violento cambio político del país. En este sentido, se produce un cambio de perspectiva en el que el regreso a México supone una derrota; por lo tanto, el ingreso dentro del grupo de los poetas real visceralistas constituye un asentamiento en la marginalidad de la derrota y del exilio que sufre el personaje al tener que huir del golpe de Estado. Emprende un viaje por Europa del cual jamás regresa ni a México ni a Chile; su condición de exiliado se acentúa con la huida de Barcelona a África para escapar de una vida decadente. Allí, el personaje se ve atrapado en un mundo del cual no puede escapar. Aunque tenaz frente a su enfermedad, finalmente desaparece en medio de una guerra en un país extranjero.

El retrato de Arturo Belano correspondería al de la juventud romántica del autor y, en cierto modo, sería a su vez un reflejo de la vida de este. El triunfo obtenido, según opino, situó a Roberto Bolaño en una nueva posición que tuvo un consecuente cambio en su forma de afrontar la vida. Como vimos en la semblanza, en pocos años pasó de escritor maldito a escritor de fama, de representar una literatura marginal a ubicarse como centro de un canon que él mismo había rehusado.

Tanto el retrato de Arturo Belano como el buen número de sus narraciones dedicadas ya al horror de los latinoamericanos en el exilio de forma general, ya al horror de la dictadura militar chilena, -tanto dentro como fuera del país- presentan a un Bolaño a quien no lo abandonó la preocupación por la tierra que lo vio nacer. Polémico convencido, no dudó en dirigir duras críticas a su país y a sus connacionales. Quizá nunca sea posible esclarecer la realidad sobre su estancia en Chile durante el golpe militar; no obstante, al margen de los hechos, tanto el relato como el esfuerzo del autor por que este formara parte de su propia biografía y su convicción de ser un exiliado son pruebas de que él mismo quiso formar parte de la historia reciente de su país, así como de su continente tanto en la realidad como en la literatura.

\section{Bibliografía}

Aguilar, Gonzalo (2002), «Roberto Bolaño, entre la historia y la melancolía», en Celina Manzoni (ed.), Roberto Bolaño. La escritura como tauromaquia, Argentina, Corregidor, pp. 145-152.

Aguilar, Paula (2008), ««Pobre memoria mía» Literatura y melancolía en el contexto de la posdictadura chilena (Nocturno de Chile de Roberto Bolaño», en Edmundo Paz Soldán y Gustavo Faverón Patriau (ed.), pp. 127-143.

Bolaño, Roberto (2004), 2666, Barcelona, Anagrama.

- (2008a), Los detectives salvajes, Barcelona, Anagrama.

- (2008b), Entre paréntesis, Barcelona, Anagrama.

- (2009a), Estrella distante, Barcelona, Anagrama.

- (2009b), Amuleto, Barcelona, Anagrama.

- (2009c), Nocturno de Chile, Barcelona, Anagrama.

- «Déjenlo todo de Nuevo. Manifiesto Infrarrealista» en www.infrarrealismo.com. (consultado, abril de 2011).

Bolognese, Chiara (2009), Pista de un naufragio. Cartografía de Roberto Bolaño, Chile, Margen.

De Rosso, Ezequiel, (2002) «Tres tentativas en torno a un texto de Roberto Bolaño", en Celina Manzoni (ed.), Roberto Bolaño. La escritura como tauromaquia, Argentina, Corregidor, pp. 55-61.

Echevarría, Ignacio (2002), «Una épica de la tristeza», en Celina Manzoni (ed.), Roberto Bolaño. La escritura como tauromaquia, Argentina, Corregidor, pp. 193-195.

Espinosa, Patricia (2002), «Roberto Bolaño: un territorio por armar», en Celina Man-
Roberto Bolaño, la memoria antiheroica del exilio chileno ADRIÁN CARRERAS RABASCO 
zoni (ed.), Roberto Bolaño. La escritura como tauromaquia, Argentina, Corregidor, pp. 125-132.

Fischer, Maria Luisa (2008), «La memoria de las historias en Estrella distante de Roberto Bolaño», en Edmundo Paz Soldán y Gustavo Faverón Patriau (ed.), pp. 145-162.

Manzoni, Celina (ed.) (2002), Roberto Bolaño. La escritura como tauromaquia, Argentina, Corregidor.

- (2002), «Narrar lo inefable. El juego del doble y los desplazamientos en Estrella distante», en Celina Manzoni (ed.), Rober- to Bolaño. La escritura como tauromaquia, Argentina, Corregidor. pp. 39-50.

Martin-Estudillo, Luis y Bagué Quílez, Luis (2008), «Hacia la literatura híbrida: Roberto Bolaño y la narrativa española contemporánea», en Edmundo Paz Soldán y Gustavo Faverón Patriau (ed.), pp. 447-471.

Paz Soldán, Edmundo y Faverón Patriau, Gustavo (eds.) (2008), Bolaño salvaje, Barcelona, Candaya.

Fecha de recepción: 21/07/2011

Fecha de aprobación: 19/10/2011 